\title{
Evolution and Emerging Trends of English Stress
}

\author{
Xingrong Guo \\ College of Foreign Languages, Shanghai Maritime University, \\ 1550 Haigang Ave, Shanghai 201306, P. R. China \\ xmguo@shmtu.edu.cn
}

\begin{abstract}
English stress is the research focus, difficulty and hotspot of linguistics. VOSviewer and CiteSpace were used to provide visualization map of research articles of English stress (1935-2022) in Web of Science dataset. This research investigated the following aspects: the key disciplinary distributions, journal network analysis, document co-citation network and citation bursts analysis, co-authorship network analysis, research hotspot and keyword network analysis, and frontier trends. Results showed that 1) the amount of international research literature on English stress has steadily increased; 2) those research focuses on the following aspects, for example, English, stress, perception, speech, language, acquisition, children, intonation, cues, etc; 3) The core research frontier trends include the following aspects: native language, spell system, acoustic analysis, speaking style, applying shadowing technique, vowel duration, sentence production, word segmentation, American sign language syllable, international Saudi Arabia students level, prosodic delay, auditory comprehension, syllabic, stress pattern, and English listener. 4) Both theoretical and empirical research are emphasized, and the empirical research shows a gradual upward trend in recent years.
\end{abstract}

Keywords: English stress, Bibliometric analysis, VOSviewer, CiteSpace.

\section{Introduction}

English stress is one of the research focuses of pronunciation teaching, recognition and language acquisition. The research paradigm, theme and depth of English stress have attracted more and more attention. A comprehensive understanding of the research process of English stress has always been the expectation of the field of English stress research. Under the framework system of bibliometrics, accurate analysis and cluster research on literature citations, topics and other contents provides a dawn for the research process, current situation, hot spots and evolution trend of English stress. This study will present bibliometric results. It will be of greater significance to the research of English stress.

CiteSpace (Chen and Leydesdorff 2013) a bibliometric analysis software developed by Chen Chaomei and VOSviewer has been paid more and more attention in the field of bibliometric research. The software VOSviewer and CiteSpace have been conducted the following analysis: the key disciplinary distribution, journal network analysis, document co-citation network and citation bursts analysis, co-authorship network analysis, research hotspot and keyword network analysis, and frontier trends.
2. Materials and Methods

Table 1: General procedure for the data collection

\begin{tabular}{|c|c|}
\hline Procedure & Specific Steps \\
\hline \multirow{3}{*}{ Data collection } & Database: Web of Science Core Citation Database. \\
\hline & $\begin{array}{l}\text { Retrieval strategy is Topics=(English stress OR English } \\
\text { lexical stress OR English sentence stress) AND } \\
\text { Type=(article) AND Language=(English) AND Research } \\
\text { fields=(Linguistics /Language Linguistics /Psychology } \\
\text { experimental /Audiology speech language pathology } \\
\text { /Education Educational Research /Acoustics)=with a time } \\
\text { span from 1935/01/01 to 2022/2/12. }\end{array}$ \\
\hline & $\begin{array}{l}\text { There were } 1975 \text { articles collected in the dataset indexed } \\
\text { by SSCI, A\&HCI, SCIE, ESCI. }\end{array}$ \\
\hline
\end{tabular}

In order to ensure the objectivity and reliability of the research, this research selects the database of web of science (WoS). The general procedure for the data collection procedure was summarized in Table 1.

\section{Results}

\subsection{Key Disciplinary Distributions}

Figure 1 displays a remarkable increase of researches about English stress over a period of 87 years.

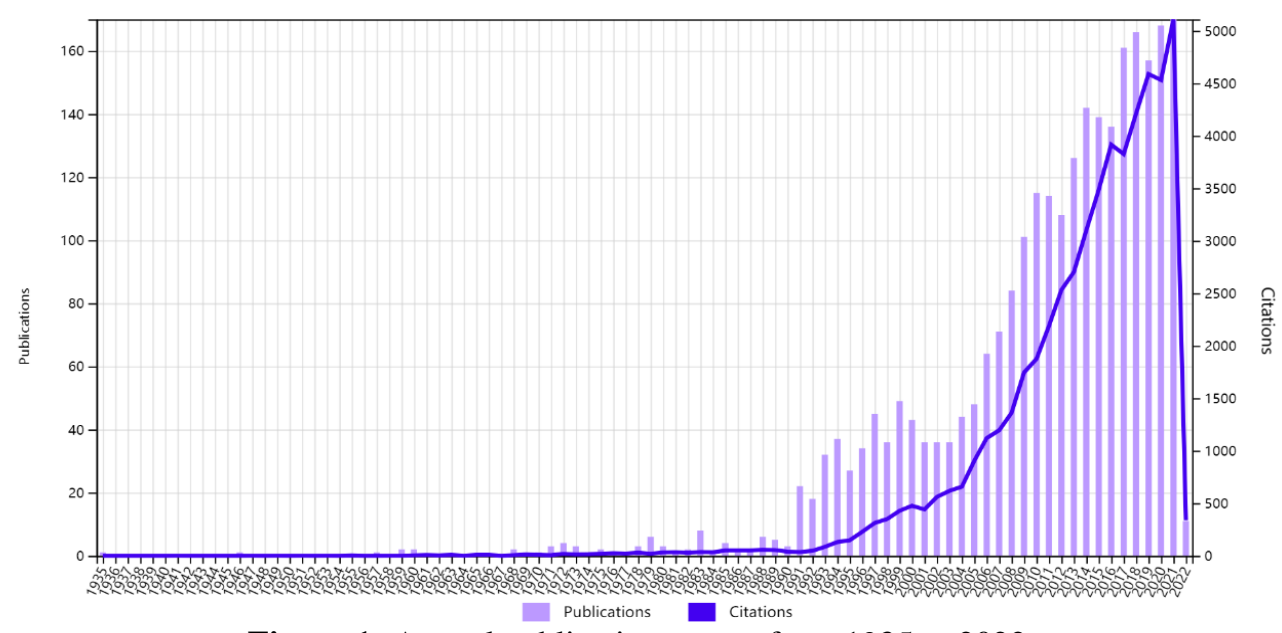

Figure 1: Annual publication counts from 1935 to 2022

Volume 9 Issue 2, 2022

www.jissr.net 
The annual trend of publications is used to investigate the development trend of English stress. As showed in Figure 1, there were less than 5 papers published annually before 1990 . There were less than 100 papers published annually during 1991-2008. In 2008, there were 84 publications. Since 2009, articles related to English stress show a rapid upward trend. There were 170 publications in 2021. There were 11 publications in 2022. Both citations and publication have increased. There were less than 100 citations annually before 1993. There were less than 1000 citations annually before 2005. There were 5129 citations in 2021. With the development of experimental linguistics technology and software, more and more studies pay attention to English stress.

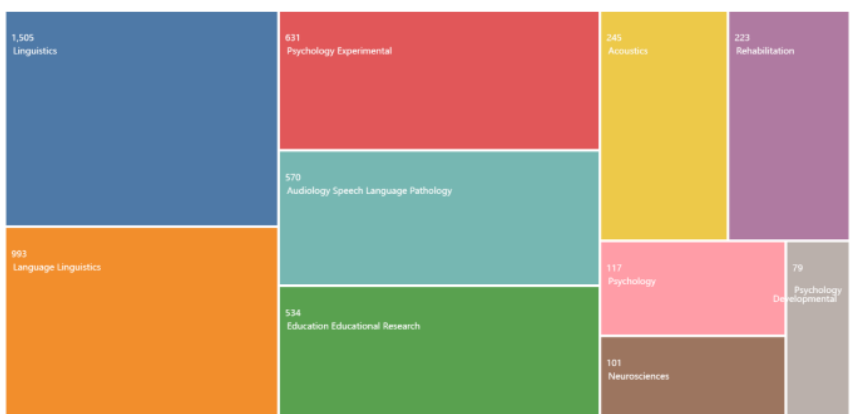

Figure 2: Key disciplinary distributions on English stress

The current international studies on English stress displays the characteristics of "multi-disciplinary cross". The five key disciplines of the most intensive study of English stress are as follows: Linguistics > Language Linguistics > Psychology Experimental > Audiology Speech Language Pathology > Education Educational Research (Figure 2). Besides, Acoustics, Psychology, Neurosciences, Rehabilitation, Psychology, Neurosciences, Psychology developmental and other disciplines continue to attach importance to English stress. The research method is rich and various, and the interdisciplinary intersection is obvious.

\subsection{Journal Network Analysis}

Figure 3 presents a knowledge map of major international journals on English stress.

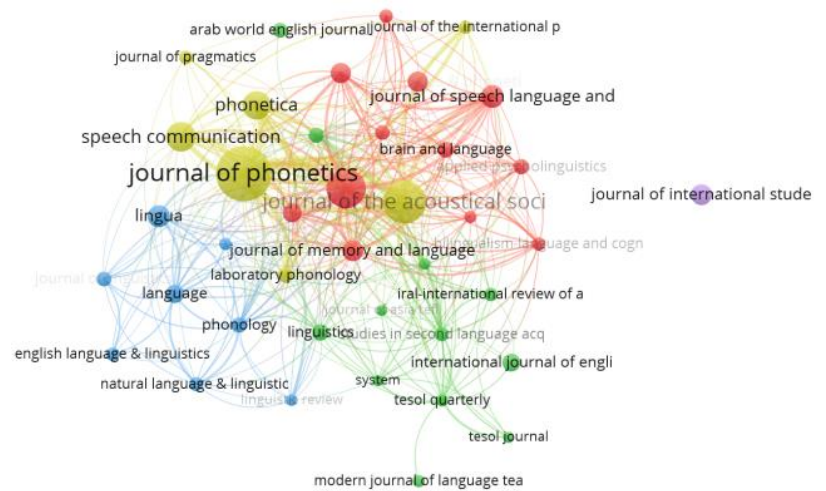

Figure 3: The top highly ranked cited journals on English stress

The "minimum number of documents of a journal" was 10. Of the 468 journals, 40 papers meet the thresholds. As shown in Figure 3, the top five highly ranked cited journals on English stress are in the following ranking order: Journal of Phonetics > Journal of the Acoustical Society of America > Language and Speech > Phonetica > Journal of Memory and
Language. These journals play prominent parts of leading and guiding researchers for the research field of English stress.

\subsection{Document Co-citation Network and Citation Bursts Analysis}

A document co-citation network refers to a network of co-citation references, which is most useful in a given research field. Figure 4 shows the salient network structure of co-cited references from 1935 to 2022, with global pruning by using a minimum spanning tree algorithm. The "minimum number of citations of a cited reference" was 42 . One-hundred papers meet this threshold out of the 80815 cited references. The network covers the publications related to English stress in the past 87 years. It comprises of 100 items, 6 clusters, 3965 links, and 26493 total link strength.

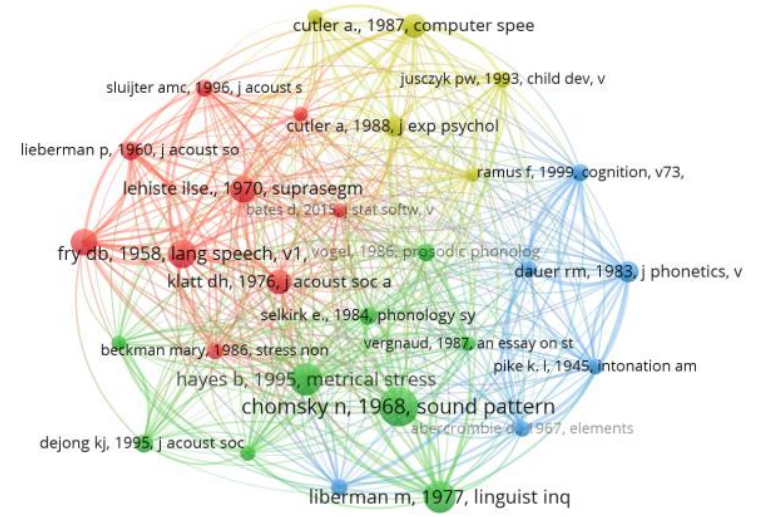

Figure 4: The reference co-citation network on English stress (1935-2022)

The top 10 most cited references were listed in Table 2.

Table 2: The top 10 most cited references

\begin{tabular}{|c|c|c|c|}
\hline \multicolumn{2}{|c|}{ Cited References } & \multirow{2}{*}{$\begin{array}{c}\text { Citations } \\
172\end{array}$} & \multirow{2}{*}{$\begin{array}{c}\begin{array}{c}\text { Total link } \\
\text { strength }\end{array} \\
578\end{array}$} \\
\hline $\begin{array}{c}\text { (Chomsky and } \\
\text { Halle 1968) }\end{array}$ & The sound pattern of English. & & \\
\hline $\begin{array}{l}\text { (Hayes and } \\
\text { Bruce 1995) }\end{array}$ & $\begin{array}{c}\text { Metrical stress theory: } \\
\text { Principles and case studies. }\end{array}$ & 141 & 625 \\
\hline $\begin{array}{l}\text { (Liberman et } \\
\text { al. 1977) }\end{array}$ & $\begin{array}{l}\text { Phonetic segmentation and } \\
\text { recoding in the beginning } \\
\text { reader. }\end{array}$ & 141 & 606 \\
\hline $\begin{array}{c}\text { (Fry 1958 } \\
1958)\end{array}$ & $\begin{array}{c}\text { Experiments in the Perception } \\
\text { of Stress }\end{array}$ & 126 & 640 \\
\hline (Fry 1954) & $\begin{array}{c}\text { Duration and Intensity as } \\
\text { Physical Correlates of } \\
\text { Linguistic Stress }\end{array}$ & 117 & 637 \\
\hline (Lehiste 1970) & Suprasegmentals & 116 & 543 \\
\hline (Klatt 1976) & $\begin{array}{l}\text { Linguistic uses of segmental } \\
\text { duration in English: acoustic } \\
\text { and perceptual evidence. }\end{array}$ & 108 & 410 \\
\hline $\begin{array}{l}\text { (A Cutler and } \\
\text { Carter 1987) }\end{array}$ & $\begin{array}{l}\text { The predominance of strong } \\
\text { initial syllables in the English } \\
\text { vocabulary. }\end{array}$ & 106 & 466 \\
\hline (Dauer 1983) & $\begin{array}{c}\text { Stress-timing and } \\
\text { syllable-timing reanalyzed. }\end{array}$ & 93 & 398 \\
\hline $\begin{array}{c}\text { (Lieberman } \\
1959)\end{array}$ & $\begin{array}{c}\text { Some Acoustic Correlates of } \\
\text { Word Stress in American } \\
\text { English. }\end{array}$ & 85 & 448 \\
\hline
\end{tabular}

The "minimum number of citations of a cited reference" was set at 60 in VOSviewer. Thirty papers meet the threshold out of the 59618 cited references. There were 34 items in 4 clusters with 552 links and 6065 total link strength. Figure 4 highlights the key literature on English stress. Fry's two papers both experimental papers on the acoustic correlates of 
English stress. Fry (1958) used synthesized speech stimuli to explore the perception of five minimal English stress pairs. Fry (1954) explored the effect of duration and intensity in English lexical stress perception. Hayes and Bruce (1995)'s book named Metrical stress theory: Principles and case studies. Chicago University Press explored a metrical stress theory. This work has been cited very much in the metrical papers.

From the perspective of the content of these literature to analyze the high influence scope of literature research, the research covers the following aspects, for example, 1) acoustic correlates of lexical stress in American English (eg., Okobi 2007); 2) second language acquisition of English stress (eg., Zhang, Nissen, and Francis 2008); 3) comparisons of the stress production among different dialects (eg., Kochanski et al. 2005); 4) infant acquisition of English stress (eg., Jusczyk, Houston, and Newsome 1999; Thiessen and Saffran 2003); 5) word segmentation in English lexical stress by infants (eg., Curtin, Mintz, and Christiansen 2005). 6) comparisons of English lexical stress segmentation between adults and infants (eg., Echols, Crowhurst, and Childers 1997); 7) lexical stress influences the word recognition (eg., Arciuli and Cupples 2006), etc. Among them, the speech analysis tools such as "Praat" and "Prosodypro" have emerged from 2006 to 2010, which is a good explanation of burst of the trend of English stress.

\subsection{Co-authorship Network Analysis}

When the "minimum number of documents of an author" was 5 in VOSviewer, 47 out of 3343 authors meet the thresholds. Table 3 shows the top 10 productive authors.

Table 3: The top 10 most productive authors

\begin{tabular}{|c|c|c|c|}
\hline Author & Documents & Citations & Total link strength \\
\hline Cho, Taehong & 13 & 265 & 11 \\
\hline Arciuli, Joanne & 13 & 297 & 7 \\
\hline Plag, Ingo & 12 & 193 & 4 \\
\hline Kim, Sahyang & 10 & 193 & 10 \\
\hline Trofimovich, Pavel & 10 & 346 & 10 \\
\hline Jarmulowicz, Linda & 10 & 122 & 5 \\
\hline Tremblay, Annie & 10 & 170 & 0 \\
\hline Jusczyk, Pw & 9 & 1538 & 2 \\
\hline Cutler, Anne & 9 & 183 & 0 \\
\hline White, Laurence & 8 & 400 & 4 \\
\hline Xu, Yi & 8 & 350 & 0 \\
\hline
\end{tabular}

As showed in Table 3, the most productive author was Cho, Taehong, who focused on investigating the prosodic feature of English. Besides, the most productive authors were Arciuli, Joanne; Plag, Ingo; Kim, Sahyang; Trofimovich, Pavel, etc. The acoustic analysis of English stress is the focus of many researchers.

\subsection{Research Hotspot and Keyword Network Analysis}

Research hotspot is one or more topics that scholars in a field are concerned about in a certain period. Table 4 shows the top 10 turning point articles of English stress detected by CiteSpace.

Table 4: Top 10 turning point articles of English stress

\begin{tabular}{|c|c|c|c|c|}
\hline Sequence & Centrality & \multicolumn{2}{|l|}{ Reference } & Frequency \\
\hline 1 & 0.27 & Praat: doing phonetics by computer (Version 4.6.33) & (Boersma and Weenink 2007) & 8 \\
\hline 2 & 0.22 & $\begin{array}{l}\text { When cues collide: use of stress and statistical cues to word } \\
\text { boundaries by 7-to 9-month-old infants }\end{array}$ & (Thiessen and Saffran 2003) & 15 \\
\hline 3 & 0.17 & The beginnings of word segmentation in English-learning infants & (Jusczyk, Houston, and Newsome 1999) & 16 \\
\hline$\overline{4}$ & 0.16 & Persistent stress "deafness": The case of French learners of Spanish & (Dupoux et al. 2008) & 19 \\
\hline 5 & 0.13 & A robust method to study stress "deafness" & $\begin{array}{l}\text { (Dupoux, Peperkamp, and Sebastián-Gallés } \\
\text { 2001) }\end{array}$ & 8 \\
\hline 6 & 0.12 & Intonational Phonology & (Ladd 2008) & 25 \\
\hline 7 & 0.12 & Analyzing Linguistic Data & (Baayen 2008) & 21 \\
\hline 8 & 0.12 & Effects of initial position versus prominence in English & (Cho and Keating, 2009) & 16 \\
\hline 9 & 0.09 & A cross-linguistic study of accentual lengthening: Dutch vs. English & (Cambier-Langeveld and Turk, 1999) & 5 \\
\hline 10 & 0.09 & Intonation & (Cruttenden, 1997) & 4 \\
\hline
\end{tabular}

The most cited turning point article on English stress research is Praat: doing phonetics by computer (Version 4.6.33) (Boersma and Weenink, 2007). Praat is a cross-platform multi-functional phonetics professional software, mainly used for digital voice signal analysis, labeling, processing and synthesis of the experiment. Praat's main function is to collect, analyze and annotate natural sound. The extensive application of Praat software enriches the experimental means of investigating English stress, so that experimental phonetics is further mature. The second important turning point paper is When cues collide: use of stress and statistical cues to word boundaries by 7-to 9-month-old infants (Thiessen and Saffran, 2003). They concluded that infants of different ages tend to use different strategies in segmentation depends on their linguistic experience. The third crucial turning-point paper is The beginnings of word segmentation in English-learning infants (Jusczyk et al., 1999). They reported that English learners may largely rely on using stress cues when segmenting words from fluent speech. The speech acquisition of infants is one of the principal subjects of international research.

Other notable turning point papers are Persistent stress "deafness": The case of French learners of Spanish (Dupoux et al., 2008) and A robust method to study stress "deafness" (Dupoux et al., 2001). These papers put forward a hierarchical model of stress "deafness", which will be known as the "Stress Deafness" Model (SDM) (Peperkamp and Dupoux, 2002). They claim that the more predictable stress is in a language, the poorer is the speakers' ability to discriminate minimal stress pairs compared to minimal phonemic pairs.

Keywords analysis can reflect the core content and research frontiers in a field. Top 20 hot keywords on English stress are shown in Table 5. 
Table 5: The top 20 hot keywords of English stress

\begin{tabular}{|c|c|c|c|c|c|c|c|}
\hline Sequence & Keyword & Frequency & TS & Sequence & Keyword & Frequency & TS \\
\hline 1 & English & 550 & 1355 & 11 & children & 82 & 229 \\
\hline 2 & stress & 522 & 1181 & 12 & intonation & 82 & 320 \\
\hline 3 & perception & 239 & 774 & 13 & cues & 72 & 249 \\
\hline 5 & language & 183 & 504 & 15 & French & 71 & 242 \\
\hline 6 & acquisition & 146 & 405 & 16 & model & 70 & 148 \\
\hline 7 & duration & 133 & 405 & 17 & rhythm & 67 & 204 \\
\hline 8 & lexical stress & 109 & 351 & 18 & pronunciation & 64 & 164 \\
\hline 9 & phonology & 109 & 268 & 19 & recognition & 60 & 211 \\
\hline 10 & patterns & 103 & 325 & 20 & segmentation & 55 & 209 \\
\hline
\end{tabular}

Note: TS: total link strength.

The function "co-occurrence + all keywords" were conducted. The "minimum number of occurrences of a keyword" was 48. Thirty keywords meet the threshold out of the 5436 keywords. As shown in Table 5, the top key words on English stress reflects that research focuses on English, stress, perception, speech, language, acquisition, children, intonation, cues, etc. A keyword co-occurrence network was displayed under the minimum spanning tree algorithm, as shown in Figure 5.

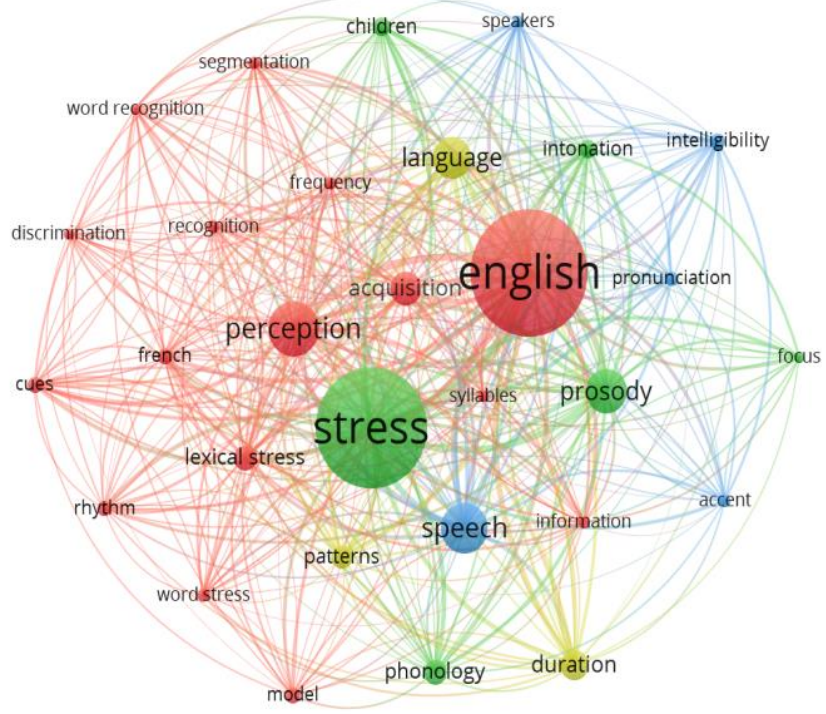

Figure 5: The keywords co-occurrence network

As showed in Figure 5, except the keywords stress and English, perception ranks the highest, which is the research hotspot of English stress and the research angle is diverse. Researchers focus on using acoustic experimental method to analyze the characteristics or acquisition of English stress.
Keyword duration is one of the important acoustic cues of English stress, which is also an important and complicated acoustic cue that causes learners to produce foreign accents. The attention of this keyword is so high that many researchers have explored the role of duration in English stress. For instance, Calibrating Rhythm: First Language and Second Language Studies (White and Mattys, 2007) and Rhythm, Timing and the Timing of Rhythm (Arvaniti, 2008).

In the core subject above, there were other topics with the highest frequency are: phonology, intonation, patterns, children, cues, recognition, information, frequency, intelligibility, rhythm, lexical access, etc. They are the key points of the literature map and the key topic of global English stress research. Studies on English stress include both theoretical and empirical studies. In recent years, the study of English stress is primarily focused on L2 acquisition. The research content is mainly focused on the phonetic aspect and the comparative study of the rhythm acquisition. The research object includes adult native English speakers, the adult second language learners, children, and infants. Of these studies, the research subject is in the majority of college students in general, but the distribution is relatively uniform, involved in each age stage, and recent studies of children acquisition of English stress increased year by year. The author suggested those valuable keywords should be strongly focused by academics.

The "Link Walk through" time line visualization method was utilized to examine and simulate the research frontiers of English stress and its research path. Figure 6 presents the results of the top 10 keywords and their impact duration of citation burst.

\section{Top 25 Keywords with the Strongest Citation Bursts}

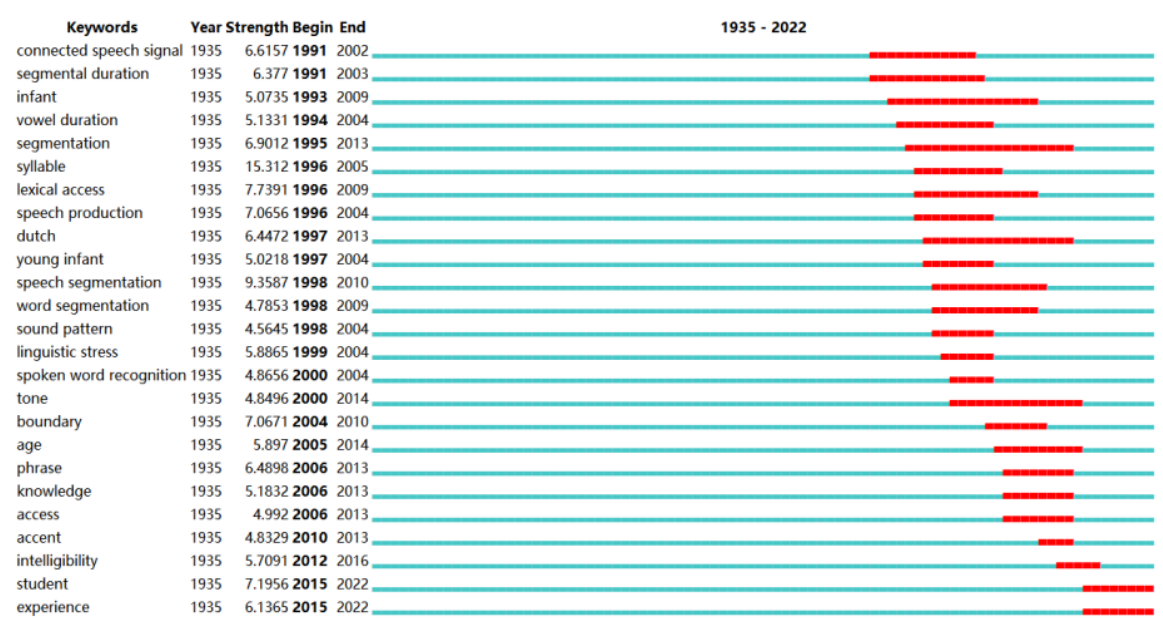

Figure 6: Top 10 keywords with the strongest citation burst 
There were 37 keywords with citation bursts by CiteSpace. Twenty-five keywords with citation bursts were included in Figure 6. Figure 6 shows the time line of keywords with strong citation bursts, and the red line representing the time period of significant change in the degree of burst. Among them, syllables and speech segmentation have stronger degree of burst and longer duration, indicating the special status of English stress study in these two aspects. Since 1991, phonetics research on such terms as connected speech signal, segmental duration, infant, vowel duration, segmentation, syllable, lexical access, speech production, Dutch, young infant, speech segmentation, word segmentation, sound pattern, and linguistic stress have soared. Since 2000, keywords with the strongest citation burst attracted increased interest includes spoken word recognition, tone, boundary, age, phrase, knowledge, access, accent, intelligibility, student and experience. These keywords are the focus of many researchers.

\subsection{Frontier Trends}

This section presents the frontier trends in the research field of English stress. Figure 7 presents a summary of the top 14 largest clusters of English stress.
At the top of Figure 7, N=271 represents the number of the nodes of the network. $\mathrm{E}=523$ is the number of the links. Density $=0.0143$. Modulartiy $Q=0.5515$ signifies that the cluster is good. Q>0.3 means that the network community structure is significant. Mean Silhouette $=0.7267$, which indicates the clusters were good. In sum, there are 14 clusters. The core research fields include the following aspects: \#0 native language, \#1 spell system, \#2 acoustic analysis, \#3 speaking style, \#4 applying shadowing technique, \#5 vowel duration, \#6 sentence production, \#7 word segmentation, \#8 American sign language syllable, \#9 international Saudi Arabia students level, \#10 prosodic delay, \#11 auditory comprehension, \#12 syllabic stress pattern, \#14 English listener. Research on native language is one of the most active research fields on English stress. Most of the study used acoustic analysis. The study of lexical stress is the major focus in the study of English stress.

A timeline knowledge map may facilitate a more in-depth analysis of a particular field of research by displaying a unique visualization of the cluster's characteristics through its duration, citation time, citation bursts, and connection inter-clusters. Figure 8 displays a timeline view English stress.

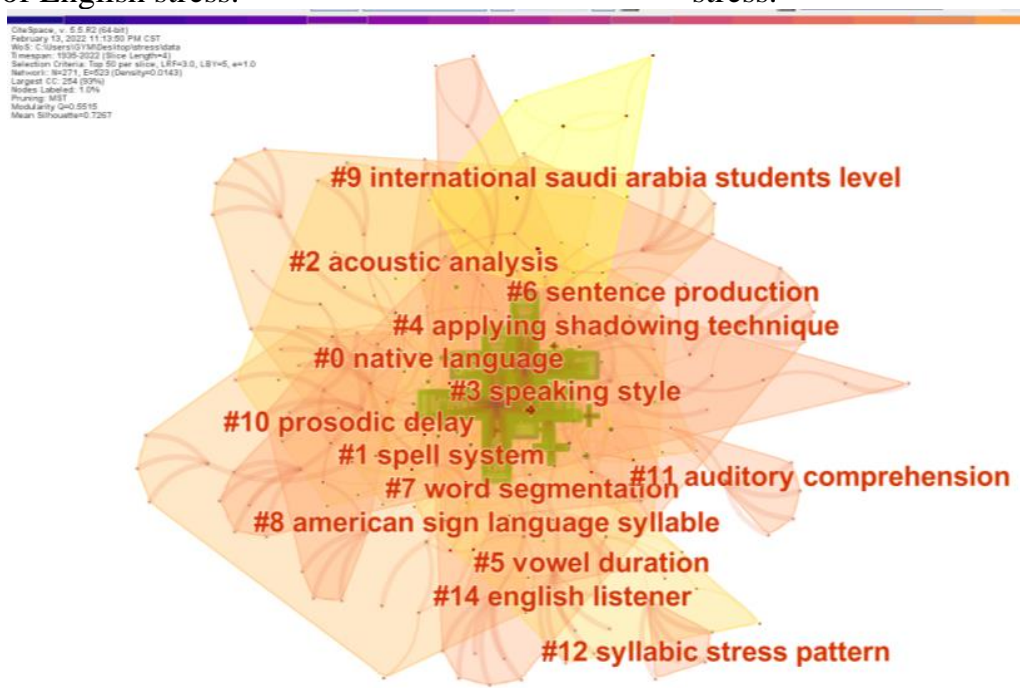

Figure 7: Co-citation Clusters Network Map

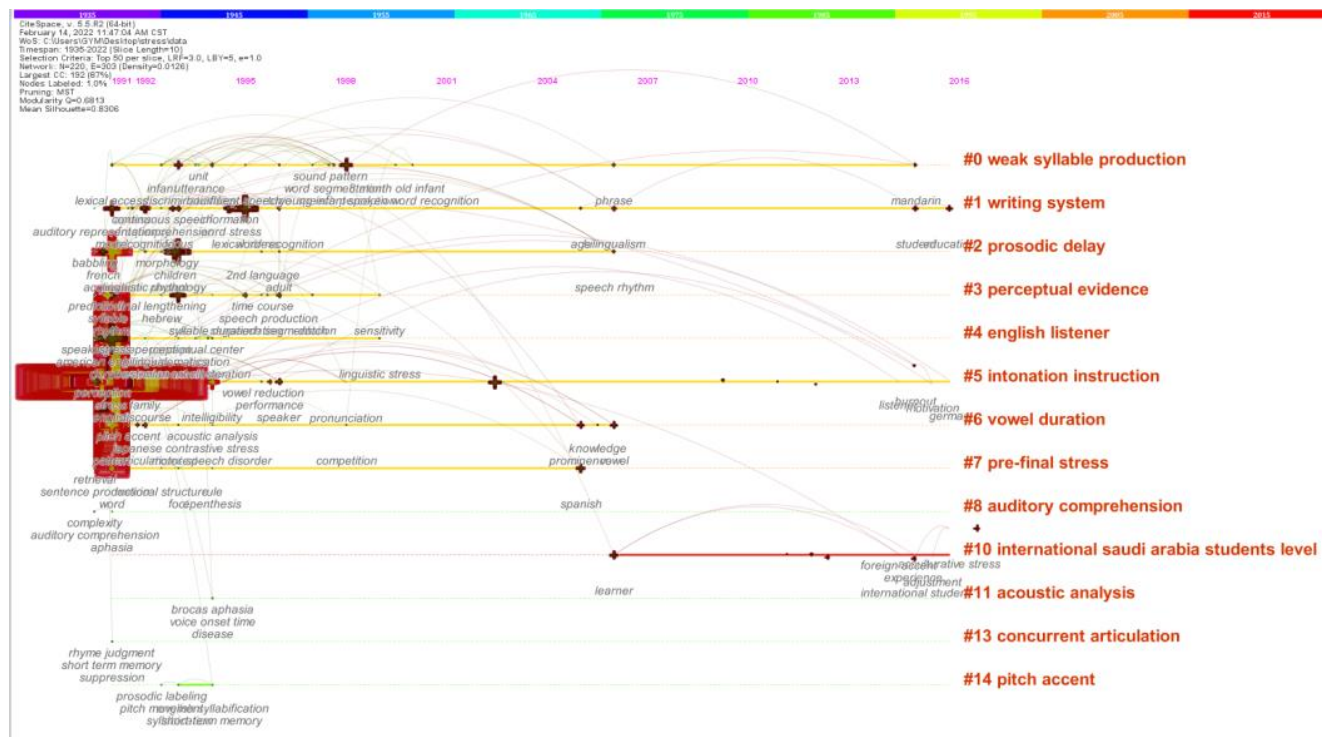

Figure 8: Timeline view of keyword analysis of English stress

Volume 9 Issue 2, 2022

www.jissr.net 
Figure 8 is a timeline view generated by CiteSpace. It displays the evolution of different clustering over time. Each cluster node is marked horizontally with the label displayed on the right side of the timeline. Each solid line represents a research direction of a study on English stress. The serial number on the right is the cluster number. The termination of the line does not mean that the research direction is dead, but rather that the knowledge base represented in that direction has not changed significantly over time. A timeline view concentrates on the relationships between the clustering and the historical span of the keywords.

The largest cluster (\#0) has 26 members and a silhouette value of 0 . It is labeled as weak syllable production by LLR, word segmentation by TFIDF, and quantity-related variation; vowel quality; spontaneous estonian; native language; bisyllabic nonword; term-memory error; lexical stress placement; British english; concurrent articulation; and silent reading.

The second largest cluster (\#1) has 25 members and a silhouette value of 0 . It is labeled as writing system by LLR, analysis by TFIDF, and lexical stress placement; British English; contrastive study; native language; bisyllabic nonword; term-memory error; quantity-related variation; concurrent articulation; silent reading; Indian English sound.

The third largest cluster (\#2) has 24 members and a silhouette value of 0 . It is labeled as prosodic delay by LLR, prosody by TFIDF, and English article variant preference; linguistic knowledge; language performance; native language; bisyllabic nonword; term-memory error; lexical stress placement; quantity-related variation; British English; concurrent articulation.

The 4th largest cluster (\#3) has 22 members and a silhouette value of 0 . It is labeled as perceptual evidence by LLR, word segmentation by TFIDF, and the native language; Indian English sound; bisyllabic nonword; term-memory error; lexical stress placement; quantity-related variation; British English; concurrent articulation; silent reading; written word.

The 5th largest cluster (\#4) has 20 members and a silhouette value of 0 . It is labeled as English listener by LLR, effect by TFIDF, and linguistic stress; sentence length; native language; bisyllabic nonword; term-memory error; lexical stress placement; quantity-related variation.

\section{Conclusions}

Based on the softwares VOSviewer and CiteSpace, this paper analyzes the publications in WoS, draws the scientific knowledge map of English stress research in recent 87 years, clarifies the most influential core documents and the key turning points in the evolution process, and combs the overall development context of English stress research. This paper defines the latest research focus of English stress and English stress in recent years, and further clarifies the core of English stress research to a certain extent.

In summary, the bibliometric analysis showed that: 1) the amount of international research literature on English stress has steadily increased; 2) the research focuses on the following aspects, for example, English, stress, perception, speech, language, acquisition, children, intonation, cues, etc; 3) The core research frontier trends include the following aspects: native language, spell system, acoustic analysis, speaking style, applying shadowing technique, vowel duration, sentence production, word segmentation, American sign language syllable, international Saudi Arabia students level, prosodic delay, auditory comprehension, syllabic stress pattern, and English listener. 4) Both theoretical and empirical research are emphasized, and the empirical research shows a gradual upward trend in recent years. The study clarifies the research context of English stress, the hot spot and the forefront tendency, and can be used as the reference for English stress study. Based on the results of co-cited reference analysis, literature during the past 87 years roughly manifests a phenomenon of acoustic analysis of English stress orientation. Especially the perspective of production and perception of English lexical stress by L2 learners with different dialect backgrounds is an urgent research field. Finally, based on the evaluation of the research situation, the paper puts forward relevant enlightenment, and holds that the multidisciplinary perspective is an important orientation of English stress research in the future.

\section{Acknowledgments.}

This research was funded by Shanghai Philosophy and Social Science Planning Education Youth Project, 2019, grant number B19005.

\section{References}

[1] Arciuli, Joanne, and Linda Cupples. 2006. "The Processing of Lexical Stress during Visual Word Recognition: Typicality Effects and Orthographic Correlates." Quarterly Journal of Experimental Psychology 59(5): 920-48.

[2] Baayen, R H. 2008. "Analyzing Linguistic Data." A Practical Introduction to Stats Using R.

[3] Boersma, P, and D Weenink. 2007. "Praat: Doing Phonetics by Computer (Version 4.6.33)."

[4] Chen, C, and L Leydesdorff. 2013. "Patterns of Connections and Movements in Dual-Map Overlays: A New Method of Publication Portfolio Analysis." Journal of the Association for Information Science and Technology 65(2): 334-51.

[5] Chomsky, N, and M Halle. 1968. "The Sound Pattern of English.” International Journal of American Linguistics: 1.

[6] Curtin, Suzanne, Toben $\mathrm{H}$ Mintz, and Morten $\mathrm{H}$ Christiansen. 2005. "Stress Changes the Representational Landscape: Evidence from Word Segmentation." Cognition 96(3): 233-62.

[7] Cutler, A, and D M Carter. 1987. "The Predominance of Strong Initial Syllables in the English Vocabulary." Computer Speech \& Language 2(3-4): 133-42.

[8] Dauer, Rebecca M. 1983. "Stress-Timing and Syllable-Timing Reanalyzed." Journal of Phonetics 11(1): 51-62.

[9] Dupoux, Emmanuel, Sharon Peperkamp, and Núria Sebastián-Gallés. 2001. "A Robust Method to Study Stress 'Deafness." The Journal of the Acoustical Society of America 110(3): 1606-18. 
[10] Dupoux, Emmanuel, Núria Sebastián-Gallés, Eduardo Navarrete, and Sharon Peperkamp. 2008. "Persistent Stress 'Deafness': The Case of French Learners of Spanish.” Cognition 106(2): 682-706.

[11] Echols, Catharine H, Megan J Crowhurst, and Jane B Childers. 1997. "The Perception of Rhythmic Units in Speech by Infants and Adults." Journal of Memory and Language 36(2): 202-25.

[12] Fry, D. 1954. "Duration and Intensity as Physical Correlates of Linguistic Stress." Journal of the Acoustical Society of America 26(1): 138.

[13] Fry, Dennis B. 1958. "Experiments in the Perception of Stress." Language and Speech 1(2).

[14] Hayes, and Bruce. 1995. Metrical Stress Theory?: Principles and Case Studies. Metrical stress theory?: Principles and Case Studies.

[15] Jusczyk, Peter W, Derek M Houston, and Mary Newsome. 1999. "The Beginnings of Word Segmentation in English-Learning Infants." Cognitive Psychology 39(3-4): 159-207.

[16] Klatt, D H. 1976. "Linguistic Uses of Segmental Duration in English: Acoustic and Perceptual Evidence." The Journal of the Acoustical Society of America 59(5): 1208-.

[17] Kochanski, G, E Grab_e, J Coleman, and B Rosner. 2005. "Loudness Predicts Prominence: Fundamental Frequency Lends Little." The Journal of the Acoustical Society of America 118(2): 1038-54.

[18] Ladd, D Robert. 2008. Intonational Phonology. Cambridge University Press.

[19] Lehiste, Ilse. 1970. "Suprasegmentals." International Encyclopedia of the Social \& Behavioral Sciences.

[20] Libcrman, I Y, D Shankweiler, A M Liberman, and C Fowler. 1977. "Phonetic Segmentation and Recoding in the Beginning Reader."

[21] Lieberman, Philip. 1959. "Some Acoustic Correlates of Word Stress in American English." The Journal of the Acoustical Society of America 31(6): 844.

[22] Okobi, A O. 2007. "Acoustic Correlates of Word Stress in American English." Massachusetts Institute of Technology.

[23] Thiessen, Erik D, and Jenny R Saffran. 2003. "When Cues Collide: Use of Stress and Statistical Cues to Word Boundaries by 7- to 9-Month-Old Infants.” Dev Psychol 39(4): 706-16.

[24] Zhang, Yanhong, Shawn L Nissen, and Alexander L Francis. 2008. "Acoustic Characteristics of English Lexical Stress Produced by Native Mandarin Speakers." Journal of the Acoustical Society of America 123(6): 4498.

\section{Author Profile}

Xingrong Guo received the $\mathrm{PhD}$ degree in Hunan University in 2017. She works in Shanghai Maritime University. Her research interests were Second Language Acquisition, International Chinese Education, and Smart education. 